\title{
Hair Transplantation into the Nape of the Neck
}

\author{
Shadi Zari ${ }^{1,2}$ \\ ${ }^{1}$ Department of Dermatology, University of Jeddah, Jeddah, KSA \\ ${ }^{2}$ Division of Dermatology, McGill University, Montreal, Canada \\ Email: shadizarimd@gmail.com
}

How to cite this paper: Zari, S. (2018) Hair Transplantation into the Nape of the Neck. Journal of Cosmetics, Dermatological Sciences and Applications, 8, 92-95. https://doi.org/10.4236/jcdsa.2018.82011

Received: March 26, 2018

Accepted: June 26, 2018

Published: June 29, 2018

Copyright $\odot 2018$ by author and Scientific Research Publishing Inc. This work is licensed under the Creative Commons Attribution International License (CC BY 4.0).

http://creativecommons.org/licenses/by/4.0/

\section{(c) (†) Open Access}

\begin{abstract}
Background: Hair loss at the nape of the neck causes embarrassment and psychological stress in a number of patients due to a variety of causes including acne keloidalis nuchae and traction alopecia. Objectives: To report a case of hair transplantation into the nape of the neck as a treatment option for scarring resulting from acne keloidalis nuchae. Methods: 700 grafts where transplanted from the occipital donor area and transplanted by follicular unit extraction (FUE) into the nape area of a male patient with recurrent scarring folliculitis in that area. Results: Hair restoration was successful with natural looking results. More tumescence than usual and skin traction was necessary to stabilize the skin during graft insertion due to soft skin in the nape area. Conclusions: Hair restoration surgery into the nape of the neck is an option for patients with hair loss in that area. FUE is the best method of hair transplantation allowing the selection of 1 and 2 hair FUE grafts in order to achieve a natural looking result in the nape area.
\end{abstract}

\section{Keywords}

Hair Transplantation, Hair Restoration, FUE, Acne Keloidalis Nuchae, Folliculitis Keloidalis Nuchae

\section{Introduction}

Hair loss at the nape of the neck causes embarrassment and psychological stress to a number of patients due to a variety of causes including androgenetic alopecia, acne keloidalis nuchae, and traction alopecia. Acne keloidalis nuchae (AKN) is also known as folliculitis keloidalis nuchae. A follicular inflammatory condition that leads to fibrotic plaques, papules and alopecia on the occiput and/or nape of the neck [1]. AKN occurs mainly in men, suggesting that androgens may play a role. This is supported by the fact that $\mathrm{AKN}$ is rare to develop before pu- 
berty or after the age of 55 [2].

One proposed mechanism for the development of AKN is that antigens of the follicular epithelium or within the follicular canal attract inflammatory cells at the level of the isthmus. The perifollicular inflammation results in weakening the follicular wall, causing the hair shaft to migrate through the wall into the dermis. The naked hair provokes a foreign-body reaction with acute and chronic granulomatous inflammation [3]. Subsequent fibrosis occurs within the dermis. This then leads to further inflammation and scarring [4].

Contributory factors include trauma, chronic irritation, seborrhea, infection, and elevated testosterone levels. The initial triggering process is mechanically induced folliculitis [5]. Sources of mechanical irritation that contribute to the development include friction from high-collared shirts, sports helmets, and other garments or equipment. The histology consists of chronic perifollicular inflammation and destruction of hair follicles [6].

Medical management focuses on prevention. Topical and oral antibiotics, and intralesional steroids are used in order to decrease inflammation and treat secondary infections. Unfortunately, treatment leads to incomplete results and recurrences are common. Surgical excision or excision by carbon dioxide laser may lead to hypertrophic and keloid scars. To our knowledge, no hair transplantation surgery has been reported in the literature to treat this issue. This is a report of successful hair transplantation into the nape of the neck in a male patient with scarring as result of acne keloidalis nuchae.

\section{Materials and Methods}

A 39-year-old male patient presented to the clinic complaining of a diffuse area of scarring alopecia on the nape area, which was present for a few years. The patient received multiple courses of antibiotics in the past. He was free of symptoms for the past 2 years and had no other medical problems. In order to assess the vascular supply of the scarring area to be transplanted before the surgery, several incisions were made using a 19-gauge needle after anaesthetizing the area with $2 \%$ lidocaine without epinephrine. There was evidence of bleeding when this was done. If not, then the area would have best been treated with surgical excision [7].

On the day of surgery, the donor and recipient areas were anesthetized with $2 \%$ lidocaine with epinephrine. At the time of initial injections, a handheld massage device (Vibration Anesthesia Device; Blaine Labs, California, USA) was applied to the injection area to distract the patient [8]. Small $0.3 \mathrm{~mL}$ syringes with a 31-gauge needle were used. 700 grafts where transplanted from the occipital donor area by manual follicular unit extraction (FUE) using $1.1 \mathrm{~mm}$ sharp serrated tip punches (Cole instruments, Atlanta, USA). Implantation of the hair into the affected areas at the nape area was done using the lion implanter. Post operatively; the patient was put on fusidic acid ointment every 8 hours for 1 week and Doxycycline $100 \mathrm{mg}$ once daily for 30 days. 


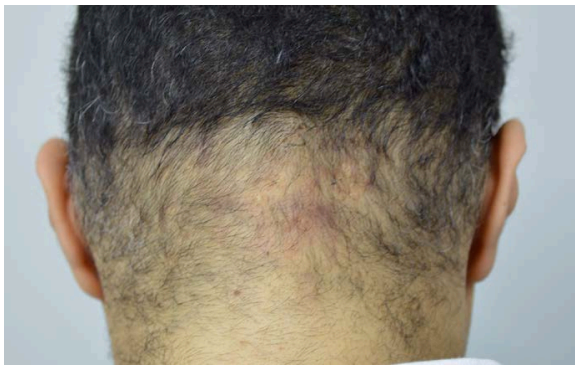

(a)

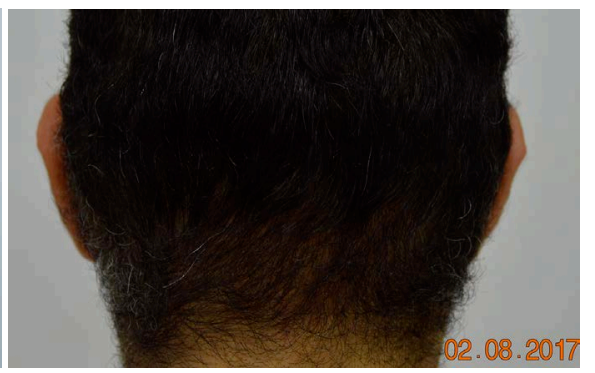

(b)

Figure 1. (a) Before hair restoration of an area of diffuse alopecia in the nape area; (b) 6 months post FUE hair restoration.

\section{Discussion}

Hair restoration was successful in the treatment of acne keloidalis nuchae with natural looking results 6 months after the procedure (Figure 1). To our knowledge, no similar case has been reported in the literature. Informed consent was obtained from the patient to report this case. Because the folliculitis was inactive for the past 2 years and the area of scarring alopecia was relatively large, hair restoration surgery was the best option for this patient. FUE was chosen as the optimum method of hair restoration, as patients with acne keloidalis nuchae have a high tendency of scarring.

More tumescence than usual and skin traction was necessary to stabilize the skin during graft insertion due to the soft skin in the nape area. The use of implanters made the transplantation much easier given the sharp downward angulation of the hair in the nape area. Implanters also allow less graft manipulation and handling, which improves graft survival.

\section{Conclusion}

Hair restoration surgery into the nape of the neck is an option for patients with alopecia in that area. FUE is the best method of hair transplantation allowing the selection of 1 and 2 hair FUE grafts without the formation of scars in these susceptible individuals, which allows achieving a natural looking result.

\section{Declaration of Conflicting Interests}

The author declared no potential conflicts of interest with respect to the research, authorship, and/or publication of this article.

\section{Funding}

The author received no financial support for the research, authorship, and/or publication of this article.

\section{References}

[1] Maranda, E.L., Simmons, B.J., Nguyen, A.H., Lim, V.M. and Keri, J.E. (2016) Treatment of Acne Keloidalis Nuchae: A Systematic Review of the Literature. Der- 
matology and Therapy (Heidelb), 6, 363-378.

https://doi.org/10.1007/s13555-016-0134-5

[2] Ogunbiyi, A.O. and Adedokun, B. (2015) Perceived Etiological Factors of Folliculitis Keloidalis Nuchae and Treatment Options Amongst Nigerian Men. British Journal of Dermatology, 173, 22-25. https://doi.org/10.1111/bjd.13422

[3] Ramos-e-Silva, M. and Pirmez, R. (2014) Red Face Revisited: Disorders of Hair Growth and the Pilosebaceous Unit. Clinics in Dermatology, 32, 784-799. https://doi.org/10.1016/j.clindermatol.2014.02.018

[4] Herzberg, A.J., Dinehart, S.M., Kerns, B.J. and Pollack, S.V. (1990) Acne Keloidalis. Transverse Microscopy, Immunohistochemistry, and Electron Microscopy. The American Journal of Dermatopathology, 12, 109-121. https://doi.org/10.1097/00000372-199004000-00001

[5] Shapero, J. and Shapero, H. (2011) Acne Keloidalis Nuchae Is Scar and Keloid Formation Secondary to Mechanically Induced Folliculitis. Journal of Cutaneous Medicine and Surgery, 15, 238-240. https://doi.org/10.2310/7750.2011.10057

[6] Alexis, A., Heath, C.R. and Halder, R.M. (2014) Folliculitis Keloidalis Nuchae and Pseudofolliculitisbarbae: Are Prevention and Effective Treatment within Reach? Dermatologic Clinics, 32, 183-191. https://doi.org/10.1016/j.det.2013.12.001

[7] Unger, W., Unger, R. and Wesley, C. (2008) The Surgical Treatment of Cicatricial Alopecia. Dermatologic Therapy, 21, 295-311. https://doi.org/10.1111/j.1529-8019.2008.00211.x

[8] Kohn, T. and Zari, S. (2016) Local Anesthesia Techniques in Hair Restoration Surgery. Journal of Cutaneous Medicine and Surgery, 20, 610-612. https://doi.org/10.1177/1203475416651052 